\title{
UNA PROPUESTA DE CLASIFICACIÓN DE LA CLASE MAGISTRAL IMPARTIDA EN LA FACULTAD DE DERECHO
}

\author{
A PROPOSED CLASSIFICATION OF THE MASTER CLASS AT THE \\ FACULTY OF LAW
}

\author{
María Francisca Elgueta Rosas ${ }^{1}$ \\ Eric Eduardo Palma González ${ }^{2}$
}

\begin{abstract}
RESUMEN: El artículo presenta los resultados de una investigación cualitativa respecto de la clase expositiva que imparte el profesorado de Derecho. Propone una clasificación y caracterización de la clase magistral. A partir de la información recabada entre estudiantes de postgrado, destaca un tipo de clase expositiva a la que denomina clase magistral 'trascendente' o 'formativa'. Se reflexiona sobre dicha clase con el fin de contribuir al mejoramiento del trabajo de aula en las Escuelas de Derecho.
\end{abstract}

Palabras clave: Clase magistral, método expositivo, didáctica universitaria, didáctica del Derecho, investigación cualitativa en Derecho.

ABSTRACT: This paper shows the results of a qualitative research about the work of Law professor in lectures. A classification and characterization of a lecture is proposed. Through the data collected primarily from undergraduate students, the paper highlights a certain type of expositive lecture which is labeled as 'trascendent' or 'formative' lecture. Such a lecture is analysed in order to contribute to the improvement of the classroom at law school.

Key words: Lecture, expository method, university teaching, teaching of law, law qualitative research.

\section{PERSPECTIVA METODOLÓGICA}

La presente investigación tiene un enfoque cualitativo ${ }^{3}$. Indaga en torno a las características que atribuyen estudiantes de Derecho (ya abogados) a la clase magistral. Procuramos entender en profundidad ${ }^{4}$ la manera en que los alumnos habían experimentado durante su

1 Doctora en Educación, Universidad de Valladolid; Diplomada en Docencia Universitaria, Universidad Metropolitana de Ciencias de la Educación; Diplomada en Gestión Universitaria, Universidad Metropolitana de Ciencias de la Educación; Diplomada en Diseño e Implementación de Encuestas, Pontificia Universidad Católica de Chile. Académica de la Unidad de Pedagogía Universitaria y Didáctica del Derecho, Facultad de Derecho, Universidad de Chile.

2 Doctor en Derecho, Universidad de Valladolid; Magíster en Historia, Universidad de Chile; Licenciado en Ciencias Jurídicas y Sociales, Universidad de Chile; Diplomado en Docencia Universitaria, Universidad Metropolitana de Ciencias de la Educación; Diplomado en Gestión Universitaria, Universidad Metropolitana de Ciencias de la Educación. Profesor de Historia del Derecho, Facultad de Derecho, Universidad de Chile. Profesor Titular. Director de Investigación, Facultad de Derecho, Universidad de Chile.

3 Los enfoques cualitativos se caracterizan por ser exploratorios. A partir de un levantamiento de información indagan los fenómenos sociales según la construcción de los sujetos investigados. Los resultados obtenidos son hermenéuticos dialécticos, esto quiere decir que es interpretativo y que persigue una síntesis de datos.

4 TaYlor y Bogdan (1987) pp. 20-23. 
formación y en su cotidianeidad, el método expositivo. En un esfuerzo de comprensión en profundidad de la experiencia vital que tuvieron durante su formación jurídica, los estudiantes nos presentaron las características de la docencia jurídica que recibieron, y más específicamente, de la clase magistral en Derecho. Seleccionamos en nuestra pesquisa a alumnos de un programa de magíster de una universidad pública tradicional chilena (abogados egresados de Facultades de Derecho de universidades tradicionales privadas y públicas, así como de privadas de reciente creación). A partir de este grupo de estudiantes o informantes ${ }^{5}$ investigamos cualitativamente el objeto de estudio (la clase expositiva o magistral).

Que la investigación sea cualitativa, implica también, que obtuvimos inductivamente los datos ${ }^{6}$. Esto quiere decir que las categorías las construimos a partir de la información que nos entregaron los estudiantes luego de aplicar tres instrumentos de investigación. Fuimos extrayendo datos e ideas relevantes a partir de lo que los estudiantes habían experimentado efectivamente durante su proceso formativo. Primero aplicamos un grupo de discusión ${ }^{7}$ y a través de los discursos de los estudiantes pudimos determinar que no existía solo una concepción acerca de la clase magistral; luego aplicamos una prueba de diagnóstico y les preguntamos expresamente por las fortalezas y debilidades de dicha clase, apareciendo la existencia de tres tipos; y finalmente para triangular la información obtenida ${ }^{8}$, aplicamos entrevistas en profundidad a otros estudiantes del programa de magíster confirmándose nuestra caracterización.

El proceso de análisis fue interactivo. Fuimos elaborando mayores niveles de generalización a través de la comparación constante ${ }^{9}$ de los resultados obtenidos con los diversos instrumentos de investigación, utilizando para ello el software Atlas-Ti $6.3^{10}$. El producto

5 El muestreo en la investigación cualitativa se caracteriza por ser intencional: se apoya en criterios internos no pretendiendo generalizar resultados, véase VASILACHIS dE Gialdino (2007) pp. 25-29.

6 Vásquez Recio y Angulo Rasco (2003) pp. 44-45.

7 El grupo de discusión es un tipo de entrevista en profundidad grupal abierto en el que a partir de un par de temas generadores, los informantes que contestan profundizan en la manera en qué significan las temáticas, pero, a la vez proponen nuevos temas.

8 Vásquez Recio y Angulo Rasco (2003) pp. 44-45. Un criterio de credibilidad de la investigación cualitativa es la triangulación, siendo una técnica en la que se recogen los datos considerando varios ángulos o perspectivas de un fenómeno que luego se comparan y contrastan. Es una estrategia eficaz para el control de la credibilidad, permitiendo garantizar la independencia de los datos respecto del investigador.

Conviene aclarar que en el proceso de triangulación o de verificación en profundidad utilizamos la triangulación por tiempo y por métodos. La triangulación por tiempo fue abordada a través de la recolección de datos en diversos momentos. En un lapso continuo temporal determinamos primero que no existía solo una clase magistral y luego con esa información, analizamos qué tipos de clase magistral habían experimentado los estudiantes; para finalizar con la triangulación a través de la verificación con entrevistas en profundidad de los tipos de clase magistral.

En lo referido a la triangulación por métodos utilizamos por un lado diversos instrumentos de investigación como son el grupo de discusión, la prueba de diagnóstico y las entrevistas individuales en profundidad; y por otro lado triangulamos entre investigadores reflexionando conjuntamente los dos académicos que presentamos este estudio, a partir de literatura especializada. Recurrimos también a un grupo focal de estudiantes del último año de la carrera de Derecho.

9 El método de comparación constante consiste en ir levantado categorías emergentes considerando actos de habla que entregan información relevante que se compara sistemáticamente en el tiempo.

10 Atlas-Ti 6.3 es un programa para análisis de datos cualitativos CAQDAS (Computer Assisted Qualitative Data Análisis Software) que sirve para la generación de teorías, por la posibilidad que da de ir levantando en un proceso inductivo categorías y familias de categorías que permite altos niveles de generalización. 
de todo este proceso analítico fue un conjunto de categorías que nos permitieron cierto grado de teorización ${ }^{11}$.

\section{LA CLASE MAGISTRAL EN DERECHO}

La expresión clase magistral no es unívoca. En las aulas de Derecho suele ser entendida en más de un significado ${ }^{12}$. Así se desprende de nuestra investigación cualitativa llevada a cabo con estudiantes de postgrado, todos ellos abogados (alumnos de un curso de Pedagogía Universitaria y Didáctica del Derecho en un Programa de Magíster de una Universidad Pública de alta selectividad). El análisis triangulado de sus respuestas nos permite identificar tres modalidades: clase magistral propiamente tal o experta; clase magistral meramente expositiva y clase magistral formativa o trascendente.

\subsection{Clase magistral propiamente tal o experta}

En la actividad académica existe la práctica de realizar conferencias de expertos para profundizar en el conocimiento acerca de un tema determinado. A este evento se le denomina clase magistral y es reconocido por los estudiantes con este nombre. Algunos señalan que la clase magistral es la lección que imparte un profesor de destacada trayectoria, sobre una materia en la que es reconocido como una persona experta. La misma no está asociada a un proceso regular de formación sino que a un evento académico cuyo objeto es, precisamente, dar a conocer el punto de vista de quien tiene el prestigio de ser una autoridad en la materia.

En este sentido la clase magistral es la oportunidad para un estudiante de escuchar a un experto reconocido y conocer de primera mano sus reflexiones sobre el tema de que se trate. El ponente presenta el resultado de sus propias investigaciones y reflexiones. Es reconocido y respetado por su saber: se trata de un maestro ${ }^{13}$.

La utilización de Atlas-Ti 6.3 nos permitió elaborar en el mismo programa notas de campo, y a través del tiempo almacenar la información en una base de datos organizada. Fue relevante la manera en que codificamos a través de interpretaciones emergentes dando diversas etiquetas a los códigos axiales.

Con esta potente herramienta informática hemos trabajado una unidad hermenéutica o conjunto de documentos primarios, en los que segmentamos el total en partes lógicas a partir de un proceso en el que buscamos la significación que le daban los informantes investigados a la clase magistral, para luego generar códigos de familias que reagrupamos en códigos axiales, los que se han representado en redes de familias.

11 Atlas-Ti 6.3 como software cualitativo permite desarrollar "Teoría Fundamentada" (Grounded Theory). Esto se basa en que "los códigos usados para organizar los datos representan las categorías teóricas que los investigadores desarrollan durante el proceso continuo de análisis. Puesto que una teoría puede ser considerada como una red de categorías, la herramienta que permite conectar códigos entre sí puede ser útil para mostrar la estructura de la teoría emergente, y por tanto el software que facilita esta función contribuirá favorablemente a su construcción” VASILACHIS DE Gialdino (2007) p. 261.

12 Véase StUCKey (2007).

13 De entre los numerosos significados de la expresión maestro, la Real Academia Española recoge en la vigésima segunda versión del Diccionario de la Lengua Española, el siguiente: "1. adj. Dicho de una persona o de una obra: de mérito relevante entre las de su clase" -versión en línea http://lema.rae.es/drae/, [fecha de consulta: 15 diciembre de 2012]. 
CODificación aXial trabajada con Atlas.Ti 6.3

Clase Magistral de Experto

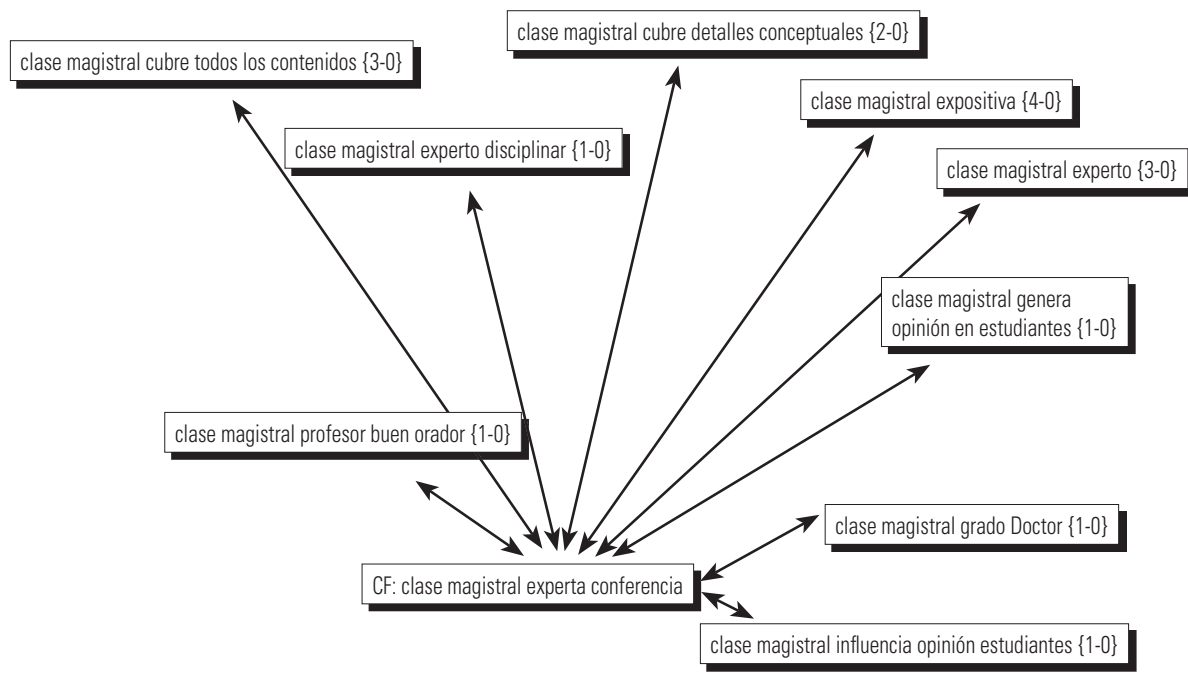

Dicha clase se caracteriza por ser expositiva y por no dar espacio a preguntas de los asistentes, que se dan por plenamente satisfechos con la sola circunstancia de haber escuchado la exposición del maestro (el formato no contempla el intercambio de opiniones). Dicen en este sentido los estudiantes:

"Es aquella en que concurre un experto, profesor, doctor en una materia y expone ante un público acerca de un tema en particular y de su competencia, lo que se realiza en un solo acto y de una sola vez"; "Para mí, una clase magistral es una clase donde se resuma todo lo positivo que debería tener una universidad, vale decir, una clase realizada en una universidad tradicional y por un profesor de acreditada excelencia académica, humano, tolerante y empático"; "Da la oportunidad a los receptores escuchar sobre un tema expuesto interesante en una ciencia o arte determinado; acerca a la comunidad universitaria a un conocimiento de alto nivel" ${ }^{\prime 4}$.

Esta actividad académica tiene una alta valoración en la comunidad académica y no solo en el mundo del Derecho. Para efectos de su diferenciación la denominaremos clase magistral propiamente tal o clase magistral de experto.

\subsection{Clase magistral meramente expositiva}

También es frecuente que la expresión clase magistral sea empleada como sinónimo de clase meramente expositiva. Y como tal, se la califica, señala Fix-Zamudio, como clase tradicional. En este caso se la entiende como expresión de una práctica docente caracterizada por el verbalismo o uso intensivo del discurso. Es sinónimo de lección catedrática ${ }^{15}$.

\footnotetext{
${ }_{14}$ Respuestas obtenidas de los estudiantes que conforman el grupo en estudio ya identificado.

15 Fix-Zamudio (s.f)
} 
Se la relaciona con una enseñanza pasiva y se la contrapone a la clase activa ${ }^{16}$. Se señala que los profesores actúan como conferencistas y los estudiantes como sujetos pasivos. Es un método expositivo que se centra en la transmisión de conocimiento. El énfasis en esta tarea impide que el profesor verifique el aprendizaje del estudiante a lo largo del proceso.

Los mismos estudiantes de postgrado a los que se solicitó caracterizar este tipo de clase, sin que previamente se les hubiesen entregado elementos de juicio o conceptos técnicos que les permitieran dicha caracterización, señalaron lo siguiente:

"La clase magistral es aquella en que el profesor se dedica a exponer un tema, sin posibilidad de preguntas o interacción del alumnado"; "La clase magistral es una clase expositiva, en que el profesor desarrolla una materia unilateralmente"; "La clase magistral se caracteriza por ser «unidireccional», esto es, el profesor que «sabe» transmite sus conocimientos a su curso sin participación de sus alumnos "que no saben», más que para realizar preguntas. El conocimiento es transmitido desde el profesor, a sus estudiantes, quienes se limitan, por regla general, a escribir o tomar apuntes del «discurso del profesor»"; "Es aquel monólogo en que el profesor como experto en el tema expone sus conocimientos u opiniones de un tema, pero sin interactuar con sus alumnos"; "He entendido la clase magistral como una exposición continua, sin pausas ni intervenciones de terceros, de un profesor sobre un determinado tema" ${ }^{\prime 1}$.

\section{Codificación Axial trabajada con Atlas-Ti 6.3}

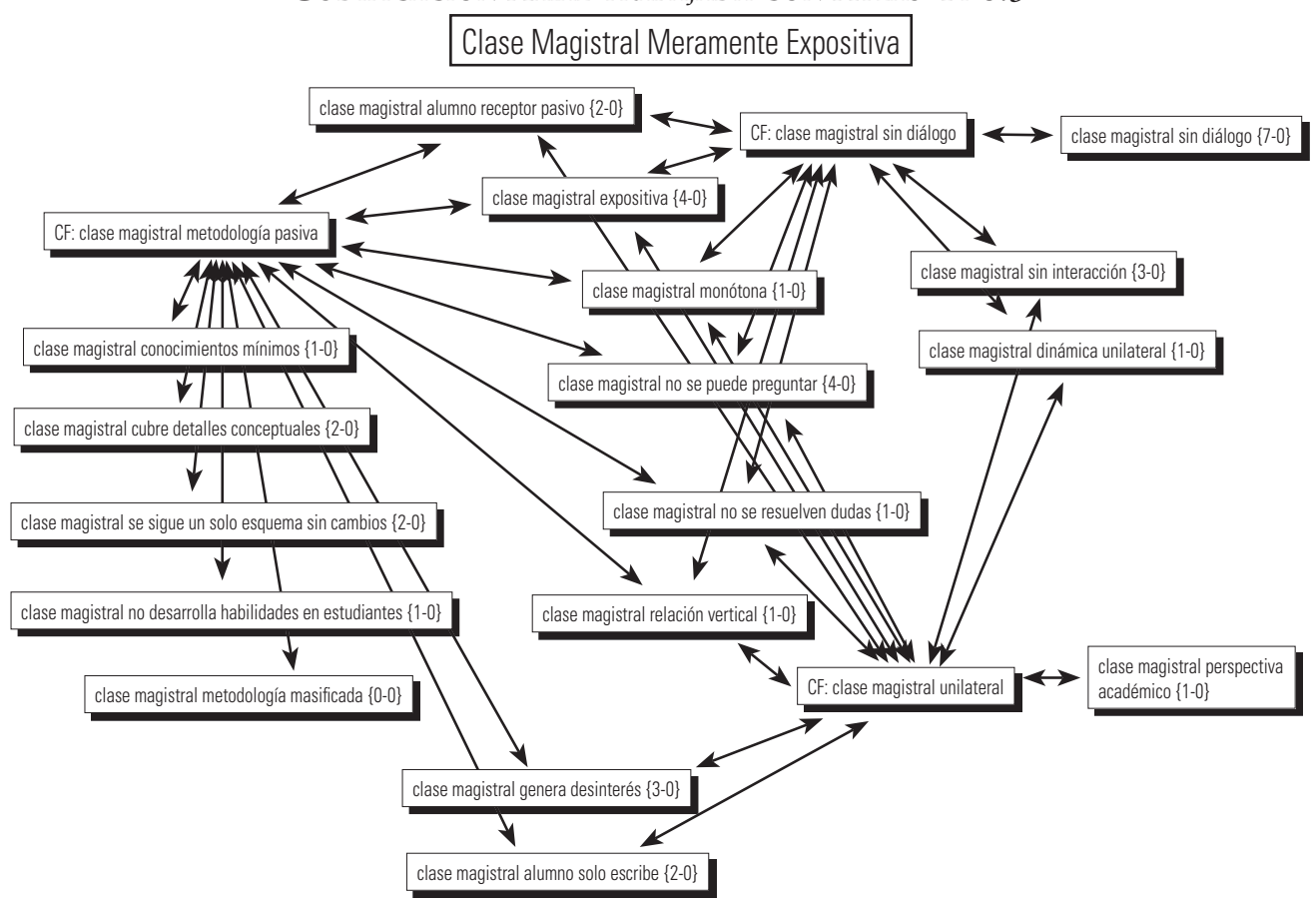

16 Véase Edwards (1993); Montoya (2010); Dasgupta (2010) y Atienza (2012).

17 Respuestas obtenidas de los estudiantes que conforman el grupo en estudio ya identificado. 
La literatura afirma que la clase magistral entendida en el sentido recién referido, viene siendo repudiada en nuestro continente desde fines de la década de $1950^{18}$. Su cuestionamiento, que todavía no configura una crisis $^{19}$, viene dado por la valoración tanto de la participación del estudiante en la clase, como de la práctica jurídica. Se ha dicho en este sentido que la conferencia y la teoría debe dar paso a la participación y la dimensión social del Derecho ${ }^{20}$. Así por ejemplo, en España, la política de formación de un espacio europeo de educación superior ha implicado la promoción de un modelo educativo centrado en el aprendizaje del estudiante, generando como consecuencia la crítica a la clase magistral: no se la considera adecuada para generar habilidades, destrezas y competencias. Por otra parte el crédito académico mide el trabajo del estudiante, lo que supone su posición activa en el proceso de formación ${ }^{21}$.

Se la ha calificado duramente, así por ejemplo, Jorge Witker señala que: “... el método tradicional de la clase magistral tiene en el monólogo del maestro, en la pasividad del alumno y en la evaluación subjetiva y arbitraria, las técnicas acordes a ese método autoritario"22. La llama indistintamente clase magistral, clase tradicional o clase conferencia.

Una caracterización semejante se encuentra en Argentina en estudios realizados desde la óptica de la sociología del Derecho:

“... se critica cómo se enseña el Derecho, estableciendo una muy fuerte correlación entre contenidos y modos de enseñanza que se hace posible por determinada forma de ejercicio docente. Así, el docente que se presenta en relación con la crítica, arriba realizada, es mayoritariamente dogmático y autoritario, ya que aparecen alocuciones tanto a la utilización monocorde de la palabra, el tiempo de habla docente (Tessio Conca y Bossio, 2001), como a ciertas prácticas de evaluación vinculadas a la comprobación de la adquisición memorística de las normas jurídicas”23.

\subsubsection{Vicios y virtudes de la clase magistral}

Invitados el grupo de abogados-estudiantes ya identificado, a reflexionar sobre las potencialidades y debilidades de la clase magistral en el tiempo presente (2012), los mismos establecieron virtudes y deficiencias para esta práctica docente.

\footnotetext{
${ }_{18}$ Fix-Zamudio (s/f). Es posible reconocer críticas aisladas desde fines del siglo XIX, véase en este sentido IRIBARNE (2005).

19 La clase magistral que aquí llamamos meramente expositiva mantiene su fortaleza en las escuelas de Derecho. Véase para el caso argentino el excelente trabajo de GonzÁlez y Cardinaux (2010); para una mirada desde Perú véase Bullard y MAC LeAN (2009); para una síntesis de la situación colombiana, Silva García (2009); para España el artículo de Pérez Lledo (2007); para México véase Flores (2006); y Madrazo Lajous (2006).

20 Véase para este aspecto, entre otros, Guerrero (1997); Maxeiner (2008) y Hopkins (2009).

21 Véase en este sentido a González Botija y Grande Aranda (2009); Belloso Martin (2009); DíezHochleiter y Rodríguez de Santiago (2008); Krause-Phelan, et al. (2011); y Shay (2012).

22 WiTKER (1985)

23 GonZÁlez, et al. (2011).
} 
Las virtudes que ellos identificaron, recuerdan algunos elementos que en su momento empleó Witker para evaluar la clase magistral ${ }^{24}$, solo que en este caso ellas se presentan como aspectos rescatables: "-Permite exponer puntos de vista y gran cantidad de materia en tiempos acotados"; "-Sirve en contextos de masificación”; "Permite cubrir todos los contenidos que el profesor quiera, con el nivel de detalle que quiera. En este sentido, facilita la labor del profesor, quien posee un esquema determinado y no se sale de él"; "Es un buen sistema en cuanto la exposición del docente puede resultar enriquecedora para el alumno"; "Si el profesor es un buen orador puede ser muy interesante" 25.

La valoración positiva indica que estos abogados, formados en distintas escuelas de Derecho, consideran como una contribución a su proceso de formación el que determinados académicos fuesen oradores interesantes que les dieron a conocer volúmenes importantes de materia. Lo que les permitió acceder al conocimiento a pesar de ser parte de clases masivas. Dicha materia fue presentada siguiendo un esquema, lo que facilitó la labor de puesta en escena de la información.

Esta valoración positiva, no constituye un obstáculo para la existencia de una significativa coincidencia entre los estudiantes en relación con los aspectos negativos de la clase magistral meramente expositiva:

"No es posible interactuar demasiado... y no permite conocer en más detalle... el tema"; "No garantiza efectividad en la transmisión del conocimiento ya que tratándose de temas particularmente áridos... el alumno se desconecta con facilidad o lo que es peor si no entiende algún tema, ante la imposibilidad de preguntar no se motiva y se genera desinterés"; "Falta de interacción al situar al alumno como un mero receptor de ideas"; “... la influencia que puede generar quien dicta la clase en la opinión de los alumnos sobre la materia”; “... imposibilidad de aclarar las dudas que se generen en los alumnos o los aportes que estos puedan hacer"; "Solo hay un expositor y los receptores no pueden interactuar con él; son selectivas y a veces de elite; no hay una cercanía entre el expositor y los oyentes; su extensión es lata, son muy largas y poco atractivas"; "Generalmente no se puede debatir por la escasez de tiempo; no ayuda a la concentración puesto que generalmente son muy largas"; "No permite interactuar. El estudiante tiende a tomar apuntes" 26 .

Hay una coincidencia en que este tipo de clase impone al estudiante una actitud pasiva que le impide ir más allá de lo que el profesor ha decidido presentar. No mantiene la

\footnotetext{
24 WitKer (1985) señaló a este respecto: transmite conocimientos al alumno mediante una exposición sistematizada de materias; expone dichos conocimientos de forma directa; impone al alumno un conocimiento "amoldado a la sistematización prefijada por el profesor"; instala al alumno en una actitud pasiva; "induce a la memorización mecánica de los conocimientos expuestos por el profesor"; no despierta una actitud crítica en los estudiantes; "permite transmitir un máximo de conocimientos en un mínimo de tiempo"; permite transmitir conocimiento no sistematizado en las fuentes; "conduce a una estructura y visión conceptual del Derecho"; no realza la necesidad de recurrir a otras fuentes de información; no exige un número determinado de alumnos para su implementación; es el sistema más barato desde el punto de vista de los recursos.

25 Respuestas obtenidas de los estudiantes que conforman el grupo en estudio ya identificado.

${ }^{26}$ Respuestas obtenidas de los estudiantes que conforman el grupo en estudio ya identificado.
} 
atención permanente del alumno y por lo tanto provoca que este no siempre procese la información que disertó el académico y además, que pierda interés en la clase. En la medida que los estudiantes estén privados de la posibilidad de consultar sus dudas, y que no haya debate, puede ocurrir que el profesor imponga determinadas visiones.

\subsection{Profesores memorables en un contexto de Clases magistrales: Del tercer} TIPO DE CLASE MAGISTRAL

Al parecer el desarrollo de la conciencia de las debilidades de la clase magistral meramente expositiva, tiene que ver con el impacto provocado en los estudiantes de un tipo de clase magistral enriquecida.

Preguntados los mismos alumnos por profesores que los habían marcado en su proceso de formación, las respuestas entregadas indicaron que hay en el seno del profesorado de Derecho una práctica de aula, todavía no generalizada, pero de enorme importancia, que implica una modificación de la clase magistral y que genera efectos muy positivos en los educandos.

La pregunta por las características que presentan los profesores que más han influido en los estudiantes en lo relativo a su desarrollo profesional, tuvo las siguientes respuestas:

“...lograba traspasar su experiencia profesional y de ese modo aprendimos muchísimo... aprendí a investigar, a reflexionar y a discutir"; "1. Profesor seguro de sí mismo, buen orador y buen vocabulario. 2. Conocedor de los nombres de sus alumnos. 3. Conocedor de temas actuales. 4. Se desarrollaba gran interacción respecto a las materias... informando y escuchando a los alumnos". 5. Se trabajaba sobre la base de ejemplos y casos concretos con una cuota de humor lo que provocaba algo de distensión en la seriedad del curso"; "Facilitaba la participación de los estudiantes en discusiones sobre temas de actualidad"; "Se trataba de clases dinámicas, en las cuales el profesor se movía en la sala. También recuerdo que, luego de ver algún tema, se presentaba en la medida de lo posible, algún ejemplo. Teníamos apuntes de clase, el cual nos era entregado con anticipación y la idea era leerlo antes de la respectiva clase. El profesor nos pedía que tratáramos de tomar pocos apuntes y de escucharlo más a él. Luego de pasar un tema venía la ronda de preguntas de los alumnos y, a veces, esto daba pie para que se generara debate. Finalmente recuerdo que hacíamos talleres prácticos sobre la materia”; “...mezclaba el Derecho con todo tipo de materias... no tenía ninguna tolerancia hacia la desidia y el desorden, sin embargo, siempre estaba abierto al debate inteligente. Esperaba lo mejor de sus alumnos y era exactamente lo que obtenía"; "Clases interactivas, con espacios para opinar libremente, de mucho análisis e interrelación de contenidos, evaluaciones directas. Ambiente distendido y al mismo tiempo profesional”; “... la interacción entre el profesor y los alumnos, de distintas maneras, a través de preguntas o conversación. Los ejemplos con casos prácticos y de conocimiento público y la libertad para opinar en clases"; "Clases estructuradas entre sí y coherentes unas con las otras; profundo conocimiento de las materias; valoración de la reflexión y del debate basado en el saber; constantes referencias a fuentes de información para posterior profundizaciones"; "Manera sencilla, pero 
precisa de explicar y abordar los temas me ha servido de modelo para desenvolverme en mi profesión”; “... a) conocimientos; b) dinamismo; c) metódicos; d) justos; e) líderes; f) amenos; g) las clases no solamente eran de derecho sino también de vida; h) cercanos; i) experiencia, no solo a través de la investigación sino que también a través del ejercicio de la profesión”; "Se trató de clases participativas guiadas por el profesor. Entregaba una serie de lecturas que había que realizar con el objeto de que la clase siguiente comenzara con una discusión acerca de un determinado tema. Luego de ello él entrega su posición y realizaba preguntas para aclarar los puntos que no hubiesen quedado claros"; "1. Los exigentes... 2. Los que te ponen a prueba... preparando tu carácter para enfrentar todo tipo de situaciones en el ejercicio de la profesión. 3. Los humanos. Son los que me han dado los valores éticos y morales para ejercer la profesión, los que me han enseñado que no todo se reduce a dinero en esta vida"; "Un tipo sencillo, que parece un ser humano y no un semidiós, claro, preciso, práctico, afable, con dominio sobre lo que enseña, con capacidad para reconocer sus errores e ignorancia"; "Profundo conocimiento y cariño por sus cursos-materias y por esta Escuela. Rigurosidad al momento de enfrentar cualquier tema"; "Sólidas. Clases rigurosas, completas, que venían de un abogado que ejercía permanentemente la profesión, y lo más importante, asociaba las instituciones a situaciones prácticas, dándonos algunos consejos que siempre recuerdo, que han sido de gran utilidad"27.

Codificación Axial trabajada con Atlas-Ti 6.3.

Clase Magistral Trascendente o Formativa

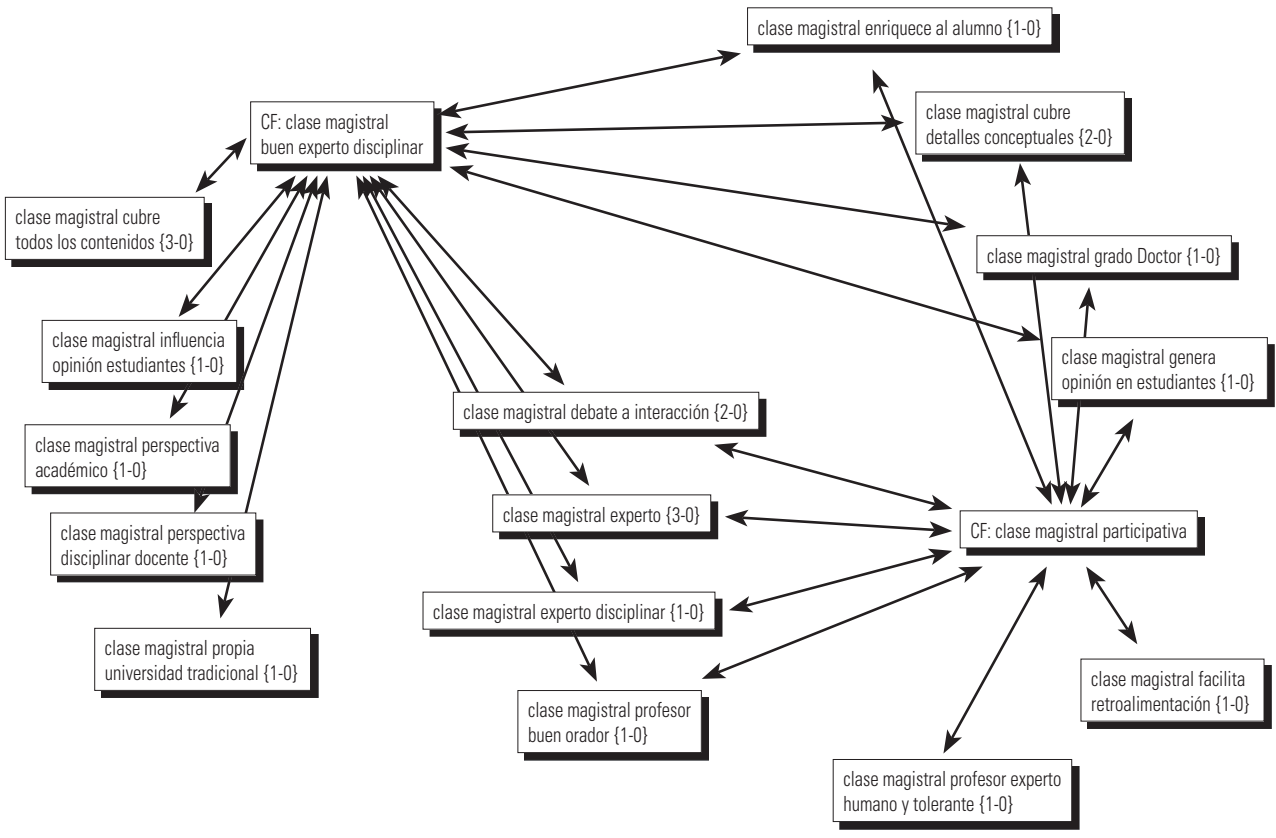

27 Respuestas obtenidas de los estudiantes que conforman el grupo en estudio ya identificado. 
Del análisis de estas opiniones se desprenden las siguientes conclusiones provisionales:

1. Que la clase magistral propiamente tal o experta, está en la base de la transformación de la clase magistral en una clase que deja huellas en los estudiantes. Es decir una clase magistral que llega a ser trascendente o formativa.

2. Dicha clase magistral trascendente o formativa presenta las siguientes características:

a) Los alumnos valoran que el profesor conozca a cabalidad la materia que expone y que la exponga de manera sistemática, sencilla, vinculándola a ejemplos casuísticos;

b) Valoran también que el académico demuestre vocación por su tarea, esto es, "cariño por sus cursos y materias" 28 ;

c) La información se transmite con una adecuada oratoria que invita a poner atención a lo que se dice, así como a participar en la clase formulando comentarios, preguntas o dando opiniones que implican participar en un debate de ideas. La participación demanda de los estudiantes interés y ocupación en conocer la materia. Lo que es valorado positivamente por el profesor;

d) Dicho saber no excluye una dimensión práctica o profesional. Contribuye a relacionar al estudiante con su entorno. El docente permite que el mismo tenga sentido en la cotidianeidad del estudiante ${ }^{29}$;

e) El saber experto no implica la construcción de una posición de dominio que cree una barrera entre profesor y estudiante. El profesor actúa con humildad, movido por un deseo de compartir a través del diálogo; de una actitud de apertura respecto del que no sabe y de la creación de un ambiente de aula grato, aunque siempre velando por la profesionalidad del trabajo;

f) El profesor incide también en la formación moral y ética del estudiante, conectándose incluso con la vida misma. La propia materia jurídica se vincula a otras materias que implican una conexión con la actualidad que se está viviendo ${ }^{30}$.

Una descripción más o menos coincidente realizó el año 2012 un grupo focal de estudiantes con el que triangulamos el proceso de levantamiento de la información.

Concluyeron que el mejor profesor que les había dado clases en su proceso de formación:

\footnotetext{
28 Frase empleada por uno de los estudiantes a los que venimos haciendo referencia.

29 La clase magistral formativa se pone en alguna medida en un punto equidistante en relación con el debate acerca de si la formación debe ser más teórica que práctica. Para una aproximación a esta cuestión véase PéREZ LLEDO (2007).

Véase para este debate en la formación jurídica norteamericana a NovelLI (2011). La autora nos da noticia del impacto que tiene en la enseñanza, la obligación de cubrir el crédito que se solicita para pagar los estudios universitarios. Lo que obliga a tener empleo tan pronto se egresa de la carrera. La queja de los estudios jurídicos de carecer los egresados de las competencias prácticas implica que dicho empleo no está garantizado. La mayor importancia de la teoría se presenta como un atentado a la empleabilidad en un sistema universitario que descansa en el pago de altos aranceles a través de préstamos.

30 Según el estudio de BAIN (2006), algunas de estas características aparecen atribuidas por los estudiantes a los mejores profesores en el sistema universitario norteamericano, sin embargo, las que faltan, inciden en calificar a la docencia norteamericana descrita como más centrada en el aprendizaje (pensamiento metacognitivo; comprensión intuitiva del aprendizaje humano; identificación de objetivos de aprendizaje para los estudiantes; evaluación en función de los objetivos).
} 
"Era un profesor que trataba de explicar todo muy bien estructurado lo que lograba en nosotros hacernos un mapa para darnos cuenta que estaba todo relacionado"; "Eran muy ordenados con la materia, muy esquemáticos. Iban de a poco avanzando en los temas; iban dando ejemplos, y si no, buscaban de una u otra forma de cómo llevarlo a la práctica. Entonces lo que era complejo al principio, luego se hacía muy sencillo"; "Estos "profes" como que trataban de eliminar esa línea entre profesor y estudiante, es decir, trataban de ser mucho más cercano (sic) no obstante al debido respeto que se debe mantener. Por eso ayudaba mucho en el proceso de aprendizaje"; "Como que nos ponía los pies en la tierra, nos explicaba la teoría pero nos decía cómo era en la práctica realmente. También nos comentaba acerca de noticias, por ejemplo de un recurso rechazado y nos preguntaba del por qué de su rechazo, en qué habían fallado, etc." 31 .

La presencia minoritaria de este tipo de profesorado que desarrolla una clase magistral que venimos llamando trascendente o formativa, indica que corre una suave brisa de cambio en las aulas de las Facultades de Derecho chilenas. Dicho cambio puede ser avalado y apoyado por la didáctica general del Derecho.

Este tipo de clase confirmaría la afirmación según la cual, varias de las deficiencias atribuidas al método expositivo son en realidad defectos del profesorado que lo usa, y no de la clase magistral. O dicho de otra manera: el método expositivo tiene un óptimo de aplicación que al lograrse genera efectos positivos en el estudiante.

Dado que la mayoría de las clases magistrales en las aulas de Derecho son más bien del tipo meramente expositiva, habría que procurar avanzar hacia una práctica expositiva trascendente. La didáctica del Derecho puede contribuir a alcanzar este desafío.

\section{CONTRIBUCIÓN DE LA DIDÁCTICA DEL DERECHO A LA TRANSFORMACIÓN DE LA CLASE MAGISTRAL MERAMENTE EXPOSITIVA}

Estamos ya en el año de 2013 y luego de más de medio siglo de crítica, la clase magistral meramente expositiva continúa siendo recurrente en la formación jurídica ${ }^{32}$. Es altamente probable que ello ocurra por razones de recreación de una tradición milenaria ${ }^{33}$. Tradición que presenta elementos positivos que la legitiman una y otra vez, en la medida que entendemos que nuestra tarea como profesores es enseñar Derecho presentando un contenido.

Sin embargo, las características negativas que se le atribuyen nos obligan a procurar su desplazamiento hacia la clase magistral trascendente o formativa.

Una primera contribución que podríamos hacer en este sentido es comparar ambas modalidades para distinguir claramente una de otra.

Dado que se trata de clases del tipo magistral, ambas se basan en la exposición que hace el profesor de una materia. El papel de la presentación por el académico de un conte-

31 Grupo focal realizado en el mes de julio del año 2012.

32 Cabe precisar que no es privativa de la formación jurídica. Para una visión crítica de la misma en la formación médica, véase Millán y VARGas (2009).

33 GonZÁlez, et al. (2011) p. 44, expresan a este respecto: “... las facultades de Derecho aún conservan formas muy tradicionales de enseñar, heredadas del pasado escolástico”. 
nido determinado es un elemento de identidad de una clase magistral ya sea del tipo propiamente tal, meramente expositiva o formativa. Dicho rol implica que el académico tiene un protagonismo en el aula. Un cambio en este protagonismo en el sentido de facilitar la intervención de los estudiantes resulta decisivo para pasar de una clase magistral a otra.

Empleando términos propios del lenguaje de los pedagogos diríamos que la clase magistral meramente expositiva (clase conferencia o clase tradicional) en la medida que gira en torno del profesor, está centrada en la enseñanza. En cambio la clase magistral trascendente o formativa al dejar espacio para el protagonismo del estudiante, mezcla enseñanza y apertura al aprendizaje.

\section{TABLA 1}

Comparación entre clase magistral meramente expositiva y clase magistral trascendente o formativa

\begin{tabular}{|l|}
\hline $\begin{array}{l}\text { Clase magistral meramente } \\
\text { expositiva }\end{array}$ \\
\hline $\begin{array}{l}\text { Forma dominante en el trabajo de } \\
\text { aula en las escuelas de Derecho. }\end{array}$ \\
\hline $\begin{array}{l}\text { Centrada en presentar los conteni- } \\
\text { dos. }\end{array}$ \\
\hline $\begin{array}{l}\text { El profesor en tanto que "experto" } \\
\text { espera ser escuchado y estima in- } \\
\text { necesaria la intervención de los es- } \\
\text { tudiantes por lo que no la fomenta. }\end{array}$ \\
\hline $\begin{array}{l}\text { El profesor experto es indiferente } \\
\text { ante la persona del estudiante. }\end{array}$ \\
\hline $\begin{array}{l}\text { Enfatiza la transmisión del saber } \\
\text { desarrollando un discurso lineal. }\end{array}$ \\
\hline $\begin{array}{l}\text { La oratoria cede ante la materia que } \\
\text { se expone: el fondo desplaza a la } \\
\text { forma. }\end{array}$ \\
\hline
\end{tabular}

La exposición se realiza ante estudiantes, importando poco si se trata de un grupo minoritario o muy numeroso.

Clase magistral trascendente o formativa

Forma excepcional en el trabajo de aula en las escuelas de Derecho.

Al interés por el contenido se agrega el interés en contribuir a la apropiación de esos contenidos por los estudiantes.

El profesor, no obstante su condición de experto, estima útil escuchar a los estudiantes para mejorar la presentación y recepción de los contenidos, por lo tanto, fomenta la intervención de sus estudiantes.

El profesor experto al escuchar a los estudiantes con respeto y ánimo de diálogo, reafirma la autoestima de los alumnos o ayuda para su surgimiento.

Interesado en la transmisión del saber recurre no solo a un discurso lineal sobre la materia, sino también a ejemplos, a la manifestación práctica del contenido y a la vivencia del mismo.

Fuerte dependencia del profesor y su discurso .

Fondo y forma tienen relevancia: el profesor procura mantener el interés del auditorio y motiva a sus estudiantes a seguir la presentación.

El interés por interactuar con los estudiantes, se ve dificultado por un grupo curso numeroso.

El fomento por parte del profesor de la intervención de los estudiantes da valor a las preguntas, comentarios y opiniones de los mismos. Profesor y estudiantes contribuyen a desarrollar el trabajo de aula

El uso de apuntes entregados con anterioridad a la clase, significa que la oralidad se complementa con el texto

Determinación de los contenidos La circunstancia de admitir preguntas, comentarios y opiniones por el profesor . implica que los contenidos a desarrollar en la clase pueden ser complementados e incluso modificados por los intereses de los estudiantes. 


\begin{tabular}{|l|l|}
\hline $\begin{array}{l}\text { Exposición del contenido sin rela- } \\
\text { cionarlo con la actualidad. }\end{array}$ & $\begin{array}{l}\text { Exposición del contenido en vinculación con su dimensión } \\
\text { práctica en el tiempo presente, lo que genera comentarios del } \\
\text { profesor sobre la actualidad. }\end{array}$ \\
\hline $\begin{array}{l}\text { Trato personal distante e indiferente } \\
\text { ante el clima de aula. }\end{array}$ & $\begin{array}{l}\text { Interés por mantener relaciones amistosas, sin que dejen de ser } \\
\text { formales, generando un clima de aula en que circulan emocio- } \\
\text { nes positivas. Interés por la persona del estudiante y el entorno } \\
\text { en que se desenvuelve el acto educativo. }\end{array}$ \\
\hline $\begin{array}{l}\text { Indiferencia ante la formación inte- } \\
\text { gral de los estudiantes. }\end{array}$ & $\begin{array}{l}\text { Interés por los contenidos que se desarrollan en clases así como } \\
\text { por la formación moral y ética de sus estudiantes. }\end{array}$ \\
\hline
\end{tabular}

De las respuestas dadas por los estudiantes de postgrado se desprende que una clase magistral es más valorada que la otra. Tal valoración tiene que ver con el hecho que la clase magistral trascendente o formativa facilita el proceso de manejo de los datos transmitidos por el profesor. Además contribuye a enriquecer el proceso formativo del estudiante en tanto que educando. En efecto, mientras la clase magistral meramente expositiva se corresponde plenamente con lo que la literatura educacional llama docencia centrada en la enseñanza, la clase magistral formativa contiene en su seno elementos que la hacen más dúctil a una propuesta docente que privilegie también el aprendizaje del estudiante.

Un cuadro comparativo de una actividad docente centrada en la enseñanza con una que mezcla enseñanza y aprendizaje, puede facilitarnos la comprensión de lo que significa la clase magistral meramente expositiva y las posibilidades de una clase magistral formativa.

\section{TABLA 2}

Docencia centrada en la enseñanza

Centrada en los contenidos. El rol del profesor es el de "especialista"

Enfatiza el saber "que"

Predominancia metodológica orientada a grupos grandes

Fuerte dependencia de los profesores

Forma de enseñanza habitual son las lecciones magistrales propiamente tales

Objetivos de aprendizaje vienen impuestos

Se evalúa a través de exámenes escritos

\section{TABLA 3}

Docencia orientada por la enseñanza-aprendizaje

El profesor cede protagonismo y promueve la intervención de los estudiantes

El profesor da noticia de los procesos cognitivos verificados en el aula

El profesor reafirma la autoestima de los estudiantes o ayuda para su surgimiento

La clase magistral incorpora las nuevas concepciones sobre aprendizaje

La clase magistral se combina con otras formas de entregar información: TICS

Se expone a los estudiantes a experiencias de aprendizaje en grupos y de forma cooperativa

Los objetivos se determinan a partir de las necesidades de formación profesional

Estudiantes trabajan en forma independiente lo que potencia sus estilos de aprendizaje

Se evalúa a través de diversos procedimientos y modalidades

El profesor actúa como experto informante así como un facilitador del aprendizaje de los alumnos 
Como ya hemos dicho, la pervivencia de la clase magistral meramente expositiva, está vinculada a una visión acerca de lo que significa aprender Derecho. Si el profesor expone un contenido sin fomentar la intervención de los estudiantes, es porque cree que la escucha de su discurso es un componente esencial de la generación de saber jurídico en el alumno. Enseñar es transmitir un saber experto que conocido; recepcionado; memorizado y recordado tal como se transmite, genera conocimiento: sabe Derecho el alumno que logra replicar lo que escuchó de su profesor, tal como lo oyó.

El profesor da a conocer a un neófito un conjunto de información que conforma el Derecho de que se trate, a quien corresponde la tarea de replicar ese saber si pretende que el académico certifique que el alumno lo conoce.

Todas las modalidades de clase magistral manejan esta misma concepción de lo que significa aprender Derecho. En todos los casos de lo que se trata es de presentar información de interés jurídico para que sea memorizada y luego recuperada.

Esto es plenamente coincidente con la visión griega de la memoria, quienes la entendían como sinónimo de conocimiento y no como una capacidad de retención ${ }^{34}$. Una idea semejante encontramos en la escolástica y en la excesiva valoración que en ella hubo de la literalidad. La adoración del texto implicaba que se conocía en tanto que se le podía recitar o replicar. Fenómeno que se vio favorecido por la escasez de libros y de copias, lo que obligaba a confiar en la capacidad de repetir textualmente lo que se había escuchado.

De ahí al silencio en la sala para escuchar al maestro hay un paso necesario de dar. Dicho silencio hacía del maestro el protagonista del trabajo de aula.

Esta visión tiene, sin embargo, un error de base. Los estudios actuales indican que memorizar es organizar información y no un mero acto de recepción replicada, es decir, mero reflejo de un objeto que se busca retener en el cerebro.

En este sentido la peculiaridad de la clase magistral formativa es que el académico procura contribuir a que el proceso de memorización y recuerdo de información del estudiante, sea más eficiente. El recurso al clima de aula, la horizontalidad, la vinculación de lo que se enseña con la realidad, son vías para facilitar la fijación y la recuperación de la materia.

Cabe presumir que al profesor que imparte la clase magistral formativa le asiste la convicción que su atención a las preguntas del estudiante y su interés por dialogar con él, favorecen que este se empape del contenido que se desea enseñar.

Los estudios sobre la memoria explican perfectamente este fenómeno: se retienen mejor las cosas que nos gustan porque en ellas intervienen la emoción y el interés, dos fenómenos que gatillan áreas del cerebro que intervienen en la memoria y el conocimiento respectivamente ${ }^{35}$.

Desde el punto de vista de la memoria cabe afirmar que la clase magistral meramente expositiva se mueve en el plano de la memoria léxica. La clase magistral formativa en el de la memoria semántica. El discurso lineal del experto reitera un texto que se considera como la medida del saber. Interesa conocer y usar las palabras dichas en la misma secuencia que se escribieron y se dijeron. Dichas palabras pueden ser efectivamente retenidas. De eso se

\footnotetext{
34 Lieury (2000).

35 Lieury (2000).
} 
encarga la llamada memoria léxica. Sin embargo, dicha retención no garantiza que el estudiante sea capaz de mantener las palabras más allá de la experiencia inmediata de la prueba. Por la sencilla razón que las mismas carecen del sentido que les da el experto que cuenta con algo que el estudiante aún no desarrolla, a saber, la memoria semántica operando en el mundo del Derecho. El estudiante puede generar en el académico la impresión de que usa las expresiones verbales con "sentido jurídico", por la sencilla razón de que este al escucharlas no puede evitar darles ese sentido. Esto permitiría entender por qué un estudiante que ha sido calificado con nota máxima en un certamen, es incapaz de demostrar en una instancia superior que "razona" con dicha materia.

El profesor que imparte una clase magistral formativa y que recurre al clima de aula, a las experiencias de vida y a las manifestaciones de las palabras que se aprenden como reglas de la vida cotidiana, facilita la memoria léxica y la memoria semántica respecto de los fenómenos que el cerebro empieza a reconocer y clasificar como Derecho. Esta última memoria, la semántica, contiene "el sentido, la significación de las cosas y las palabras... constituye nuestra memoria más poderosa... es abstracta, solo retiene la significación de las cosas sin retener las palabras exactas (lo que hace la memoria léxica)... conserva las informaciones durante más tiempo" 36 . Lieury afirma que "la memoria con análisis semántico es más provechosa que el simple análisis léxico... -de hecho- la comprensión aparece como el motor de la memoria semántica, mientras que el aprendizaje de memoria es el motor de la memoria léxica" ${ }^{37}$.

En todo caso cabe destacar que Lieury señala que la lectura como medio facilitador de la memorización es superior a la audición. Los ojos pueden realizar regresiones ante las palabras difíciles lo que implica una autorregulación según la dificultad del texto. También afirma que las imágenes son superiores a las palabras, teniendo presente que el cerebro las fabrica y que no son fotografías de la realidad sino "imágenes de síntesis bien ordenada en la biblioteca de la memoria gráfica" 38 . Y que la lectura es mejor que las imágenes.

La clase magistral trascendente o formativa puede ser la puerta que lleva a la ruta de la enseñanza-aprendizaje, es decir, una relación profesor-estudiante en que sin perder relevancia ni el contenido ni el experto, cobra también importancia el aprendizaje del estudiante. El protagonismo que logra el estudiante puede permitir dar un paso para introducir el cambio cualitativo de la relación profesor-estudiante, de modo tal que empiece a ser relevante el aprendizaje de este último.

La noción aprendizaje no es sinónimo de mera memorización y reiteración de lo presentado por el profesor, sino, la descripción de un fenómeno experimentado por el estudiante y que implica la modificación de su capacidad cognitiva.

Se entiende por cognición "el conjunto de procesos que permiten el procesamiento de la información y el desarrollo del conocimiento. Estos procesos se denominan «funcio-

\footnotetext{
36 Lieury (2000) pp. 72 y 75

37 Lieury (2000) pp. 81 y 82.

38 Lieury (2000) p. 99.
} 
nes cognitivas»" ${ }^{\prime 3}$. Entre estas tenemos, la memoria, el aprendizaje, el razonamiento y la planificación.

Aprender es modificar las capacidades cognitivas. Memorizar por su parte es hacer operar la memoria, es decir, "el conjunto de los mecanismos, tanto biológicos como psicológicos, que permiten registrar y restituir las informaciones" 40 .

Esto no nos debe llevar a despreciar la memoria y a presentarla como opuesta al razonamiento, porque la capacidad de recordar está en la base de un buen razonamiento, entendido este como "conjunto de los mecanismos que permiten manipular elementos, recombinarlos para deducir cosas nuevas" ${ }^{\prime 1}$.

Es probable que un profesor que valora la clase magistral formativa esté abierto a innovar, introduciendo en sus clases acciones destinadas a fomentar el aprendizaje de sus estudiantes. El interés que muestra por sus personas le hará receptivo a la noción estilos de aprendizaje y en esta misma medida a combinar la clase expositiva con metodologías activas.

El interés que exhibe en el diálogo y el debate lo hace un potencial conocedor de los fenómenos cognitivos que acontecen en el aula. Así las cosas, la clase magistral trascendente se transforma en la puerta hacia una actividad de aula centrada en el aprendizaje.

\section{BIBLIOGRAFÍA CITADA}

Atienza, Soledad. (2012): “The evolution of Legal education in Spain”, Journal of Legal education, vol. 61, No 3: pp. 468-478.

BAIN, Ken (2005): Lo que hacen los mejores profesores universitarios (Universidad de Valencia, España, primera edición habla inglesa 2004).

Belloso Martin, Nuria (2009): "La construcción del Espacio Europeo de Educación Superior-EEES- en las universidades españolas: la metodología docente y el proceso de evaluación del aprendizaje del alumno en los estudios jurídicos”, Revista Seqüencia, número 59: pp. 219-251.

Bullard, Alfredo y Mac Lean, Ana Cecilia (2009): "La enseñanza del Derecho ¿cofradía o archicofradía?”, Revista sobre enseñanza del Derecho, año 7, No 13: pp. 21-47.

DAsGupta, Lovely (2010): "Reforming Indian Legal Education: linking Research and Teaching”, Journal of Legal Education, vol. 59, No 3: pp. 432-449.

Díez-Hochleiter, Javier y Rodríguez de Santiago, María (2008): "El proceso de Bolonia y el nuevo plan de estudios de Derecho de la UAM", Revista Jurídica de Universidad Autónoma de Madrid, No 18: pp. 131-147.

EDwards, Harry. (1993): “The Growing Disjunction between Legal Education and the Legal Profession”, Michigan Law Review, vol. 91, No 8: pp. 2191-2219.

Flores, Imer (2006): "Prometeo (des) encadenado: la enseñanza del Derecho en México", Academia. Revista de enseñanza del Derecho, año 4, No 7: pp. 51-81.

\footnotetext{
39 OCDE, CERI (2007) p. 37.

40 Lieury (2000) p. 59.

41 Lieury (2000) p. 61.
} 
Fix-Zamudio, Héctor (s/f): "Algunas reflexiones sobre la enseñanza del Derecho en México y Latinoamérica". Disponible en http://biblio.juridicas.unam.mx/libros/1/247/5.pdf [fecha consulta: 15 de octubre 2012].

GonzÁlez Botija, Fernando y Grande Aranda, Juan Ignacio (2009): “Apliquemos Bolonia en las universidades españolas: en defensa del Espacio Europeo de Educación Superior en la carrera de Derecho", Revista Universitaria Europea, No 10: pp. 107-154.

GonzÁlez, María y Cardinaux, Nancy, comp. (2010): Los Actores y las prácticas. Enseñar y aprender Derecho en la UNLP (La Plata, Editorial Edulp, Argentina).

GonzÁlez, Manuela, Marano, María Gabriela, Bianco, Carola y Carrera, María Cecilia (2011): "Estado del arte de la educación jurídica a diez años del Congreso Nacional de Sociología Jurídica”, Academia. Revista sobre enseñanza del Derecho, año 9, No 17: pp. 175-218.

Guerrero, Roberto (1997): "La enseñanza del derecho en Chile: una visión crítica”, Revista chilena de derecho, vol. 24, No 1: pp. 21-26.

Hopkins (2009): "Teaching evidence law within the framework of a trial: relating theory to practice as students take to their feet and take responsibility for the trial narrative", Journal of the Australasian law teachers Association, vol 2, No 1 y 2: pp 173-184.

Iribarne, Héctor Pedro (2005): “Acerca de la enseñanza del Derecho. Limitaciones que impone la dogmática. Cauces para su superación” Disponible en http://www.revistapersona.com.ar/Persona45/41Iribarne.htm

Krause-Phelan Tonya, Larson, Joni, Miller Nelson P., Kim O’leary, Derek Witte, and Vickie Eggerskrause (2011): "Using a Faculty Inquiry. Process To Examine Student Responsibility for Learning”, Journal of Legal Education, vol. 61, No 2: pp. 280-299.

Lieury, Alain (2000): La memoria del alumno en 50 preguntas (Editorial Fondo de Cultura Económica, México).

Madrazo Lajous, Alejandro (2006): “QQué? ¿Cómo? y ¿Para qué? Análisis y crítica al modelo tradicional de enseñanza del Derecho en México", Academia. Revista de enseñanza del Derecho, año 4, No 7: pp. 167-247.

Maxeiner, James R. (2009): "Integrating Practical Training and Professional Legal Education", en Klabbers, J. y Sellers, M. (eds.), The Internationalization of Law and Legal Education, Vol. 2. Disponible en: http://www.springer.com/law/book/978-1-40209493-4.

Millán, Teresa y Vargas, Nelson (2009): “Clases magistrales en carreras de salud: reflexiones basadas en evidencias y experiencias” Disponible en: http://www.redclinica.cl/HospitalClinicoWebNeo/Controls/Neochannels/Neo_CH6258/deploy/clases_magistrales.pdf

Montoya, Juny. (2010): "The Current State of Legal Education Reform in Latin America: A Critical Appraisal”, Journal of Legal Education, vol. 59, No 4: pp. 545-566.

Novelli, Celeste (2011): "Cuando la enseñanza del Derecho es noticia: informe sobre la discusión publicada en el New York Times en el mes de noviembre de 2011”, Academia. Revista sobre Enseñanza del Derecho, año 9, No 18: pp. 251-258.

OCDE, CERI (2007): La Comprensión del cerebro. El nacimiento de una ciencia del aprendizaje (Santiago de Chile, Ediciones Universidad Católica Silva Henríquez). 
Pérez Lledo, Juan Antonio (2007): “Teoría y práctica en la enseñanza del Derecho”, Academia. Revista de enseñanza del Derecho, año 5, No 9: pp. 85-189.

Real Academia Española: "Vigésima segunda versión del Diccionario de la Lengua Española” Disponible en: http://lema.rae.es/drae/

SHAY, Giovanna (2012): "Inside-Out as Law School Pedagogy", Journal of Legal Education, vol. 62, No 2: pp. 207-217.

Silva García, Germán (2009): "Cambio y resistencia en la concepción y organización de los Programas de Derecho”, Academia. Revista sobre enseñanza del Derecho, año 8, No 14: pp. 173-205.

StuckeY, Roy et al. (2007): “Best Practices for Legal Education” Disponible en: http:// cleaweb.org/best-practices

TaYlor, Steven, Bogdan, Robert (1987): Introducción a los métodos cualitativos de investigación (Editorial Paidós, Barcelona).

Valles, Miguel (2007): Técnicas cualitativas de investigación social. Reflexión metodológica y práctica profesional (Editorial Síntesis S.A., Madrid).

VAsilachis de Gialdino, Irene (coord.) (2007): Estrategias de investigación cualitativa (Argentina, Editorial Gedisa).

VÁsquez Recio, Rosa y Angulo Rasco, Félix, comp. (2003): Introducción a los estudios de casos. Los primeros contactos con la investigación etnográfica (Ediciones Aljibe, España).

Witker, Jorge (1985): “Técnicas de enseñanza del Derecho” Disponible en: http://biblio. juridicas.unam.mx/libros/3/1070/pl1070.htm 